\title{
В. В. Ванслов
}

\section{Научно-технический прогресс и культура}

Аннотация: в эпоху техногенной циивилизации возникает и становится все более значительным противоречие между научно-техническим прогрессом и духовной культурой. Возрастают комфортность и внешние блага жизни, создаются новые возможности для технологий искусств и материальной основы художественной культуры. Однако негативные последствия научно-технического прогресса ведут ко все большим нарушениям экологического баланса, создают социальные явления, способствующие обесценению и деградации человеческой личности. Представления о безграничных возможностях и об исторической бесконечности научно-технического прогресса ошибочны. В будущем неизбежен его коллапс и техногенная катастрофа, которые приведут к смене направления исторического развития. В новой (нетехногенной) эпохе научно-технический прогресс потеряет приоритетное значение и будет подчинен задачам духовной культуры.

Ключевъе слова: культурология, техногенная циивлизация, научно-техническая революция, личность, духовная культура, художественное образование, средства массовой информации, манипуляция сознанием, техногенная катастрофа, историческое будущее.

$\mathrm{B}$ современных общественных науках период в истории человечества, начавшийся после эпохи Возрождения и продолжающийся до сих пор, принято называть техногенной цивилизацией. Ее отличительная особенность состоит в том, что приоритетное значение в развитии общества приобрели основанные на точных науках достижения в сфере промышленности и техники, постепенно достигавшие все больших масштабов. Это обеспечивало возможность возрастания комфортности и внешних благ человеческой жизни, стремление к максимальному овладению которыми пронизало все общество и наложило отпечаток на характеры, поведение и судьбы людей.

Научно-технический прогресс происходил с ускорением и ныне приобрел такие бешеные темпы, что за последнее десятилетие пройден путь, на который ранее потребовался бы целый век. Современные мегаполисы - с их «марсианской» архитектурой, захватившим души интернетом, электронной почтой, спутниковым телевидением и мобильными телефонами, фантастически огромными аэропортами и транспортными пробками, чудесами изобретений и экологическими проблемами, с их кишащими муравейниками жителей и одиночеством в толпе, с экстатическими вакханалиями ревущих спортивных стадионов или массовых зрелищных шоу и со съеживающимся, словно шагреневая кожа, слоем гуманитарной интеллигенции, с политическими демонстрациями и предвыборным пиаром уже сотнями опутывают Землю. Они как-то незаметно и внезапно поднялись на наших глазах из глубин ХХ в. (тоже достаточно безумного, но все-таки без такой абсолютной технологизации всей жизни людей).

Если ранее плодами научно-технического прогресса пользовались преимущественно господствующие классы, то в середине XX в. во всем цивилизо- ванном мире возникло, по определению социологов, общество массового потребления. Без поддержания такого общества ныне не могут удержаться на своих вершинах никакие властные структуры, поэтому оно растет во все больших масштабах. И уже сейчас для производства невиданно гигантского объема потребляемого продукта не хватает натуральных ресурсов, так что человечество вынуждено прибегать к суррогатам и к химии в производстве как вещей и окружающего предметного мира, так и продуктов питания. Непрерывное и все ускоряющееся увеличение численности населения, уже достигшей 7 млрд. человек, приведет к тому, что станет остро недоставать не только продуктов питания (все более искусственных), но и не загрязненных воды и воздуха. Эта тенденция будет нарастать, и она является безусловной угрозой существованию людей, одним из гибельных последствий научно-технического прогресса. О других таких последствиях речь впереди.

Достижения прогресса не были гарантом непрерывного движения человечества по восходящей линии. В истории наряду с периодами расцвета были явления одичания, взлеты разума чередовались с прорывами варварства, возрастание добра сменялось все более изощренными и ужасными формами зла. Прогресс науки и техники порою означал регресс человека и межличностных отношений.

Тем не менее, промышленные успехи нередко порождали упоение прогрессом, восторг перед ним и воспевание его. Сформировавшийся в середине XIX в. в Европе позитивизм в науке и философии (Г. Спенсер, О. Конт и др.) преклонялся перед прогрессом. Отрицая философские обобщения и общие теории, сводя науку к утилитарным задачам, он видел ее назначение именно в обосновании производственных достижений. Научно-технический 
прогресс воспевали также футуристы всех стран и отечественные авангардисты 1920-х гг., стремившиеся служить ему и эстетизировать его достижения. Можно назвать и других достаточно многочисленных поклонников и апологетов прогресса.

Но гораздо большее значение имели сменявшие друг друга, начиная с середины XVIII в., волны его критики. Она доказывала, что именно на основе прогресса возникло буржуазное общество со всеми его пороками и неприглядными сторонами, что оборотной стороной созидательности прогресса являются его разрушительные последствия. Критика эта велась во имя гуманизма, осуждая и отрицая то, что гуманизм подрывало. Ж. Ж. Руссо первым отметил, что технические достижения не делают людей счастливее. С тех пор и вплоть до наших дней эта мысль варьируется и разрабатывается во многих философских и социологических учениях.

Мощная волна оппозиции научно-техническому прогрессу прокатилась в эпоху романтизма. Счастье не в комфорте, богатстве и власти (они только портят людей), а в ценностях духовных и нравственных. Утверждая это, романтики видели в современном обществе измельчание личности, господство меркантилизма и чистогана, развитие хищничества и жестокосердия. Ненавидя все это, они отворачивались от современности, воспевая докапиталистическое прошлое, уходя в субъективные фантазии, мечтания и грезы или уносясь в воображении в дальние экзотические страны.

Писатели-реалисты XIX в. продолжили линию критики, избавившись от романтических иллюзий, трезво сознавая и правдиво показывая антигуманизм современной жизни, но стремясь не уйти от мира, а воздействовать на него (достаточно напомнить О. де Бальзака, Ч. Диккенса и Э. Золя, Ф. М. Достоевского и Л. Н. Толстого). У каждого из них были свои иллюзии, но главное - необычайная глубина в художественном постижении человека, тайников его психологии и враждебных ему, принижающих и разрушающих его сил. Эстетики У. Моррис и Д. Рескин показали, как современная им промышленность убивала древние ремесла и народное искусство, и пытались их возродить. Эта идея увлекала и ряд отечественных деятелей художественной культуры Серебряного века.

Под знаком критики развивались многие философские и социологические учения Европы и Америки XX в. (Франкфуртская школа, а также Г. Маркузе, П. Гудман, К. Хоффнер и др.). Во все эпохи она велась во имя гуманизма, не совместимого с негативными последствиями прогресса. Однако уже в конце XIX в. возникли сомнения в гуманистических ценностях и идеалах, а в XX в. под влиянием невиданных ранее сокрушительных катастроф, мировых войн и кровавых революций, злодеяний фашизма и тоталитарных диктатур, терроризма и межнациональных конфликтов многим мыслителям и художникам, ученым и общественным деятелям стало казаться, что эти ценности и идеалы вообще оказались утопией, красивой, но не оправдавшей себя иллюзией, что они исчерпаны, утратили свое значение, ушли в прошлое, и развитие мира определяют ныне совсем другие силы.

У композитора Г. Малера есть песня, музыку которой он потом включил во Вторую симфонию. В песне рассказывается, как святой Антоний проповедовал добро рыбам, но те не слушали его и продолжали поедать друг друга. Подобных примеров, свидетельствующих о разочаровании в гуманизме, в силе добра и художественного воздействия на людей можно было бы привести множество.

Авангардистское искусство XX в. прореагировало на подобные широко распространившиеся умонастроения. Многие течения символизма и модернизма на новом этапе и в новых условиях продолжили и развили романтическую критику. Они показали обесчеловечивание человека, стандартизацию усредненной личности, одиночество и затерянность человека в миpe, алогизм бытия, хаотичность и непредсказуемость истории, катастрофичность и бесперспективность существования. Достаточно напомнить о сюрреализме и театре абсурда, о Ф. Кафке и писателях-экзистенциалистах (А. Камю, Ж.П. Сартр). Все это - результат подчинения человека власти технической цивилизации, создающей общество, где человек из субъекта творческой деятельности превращается в объект владычества чуждых и непонятных внешних сил, в деталь технологического и общественного механизма.

Несмотря на все разочарования в идеалах и ценностях, развитие гуманизма в истории все-таки происходило и происходит. Если бы это было не так, то человечество просто погибло, было бы раздавлено силами зла и погребено под развалинами собственной цивилизации, рухнувшей из-за неразрешимых противоречий. Такая возможность не исключена в будущем, о чем будет речь далее.

В развитии гуманизма играли роль, конечно, и религия с ее человечными заповедями любви и милосердия, и гуманитарные науки, особенно философия, обращенные к человеку и направленные на его благо и возвышение. Но главное значение принадлежало и принадлежит мировому искусству. Именно оно, охватывающее системой своих видов все грани человеческого бытия, развивает человека как творческую личность, совершенствуя и углубляя его восприятие мира, пробуждая фантазию, заставляя переживать, чувствовать, эмоционально реагировать на реальные явления, побуждая к осмыслению жизни в целом. Воспевая красоту, оно утверждает добро. Доставляя 
эстетическое наслаждение, заставляет мыслить. Оно формирует личность человека в целом. Если наука делает человека ученым, то искусство делает его Человеком, т. е. развивает его творческие начала, образующие своеобразие личности. Такова сила художественных вершин человечества. При этом искусство влияет на жизнь не только индивида, но и общества в целом. И не только через формирование духовного мира его членов, но и непосредственно. Оно объединяет людей, преодолевает некоммуникабельность, летит через границы, помогает взаимопониманию наций. Всем этим определяется великое гуманистическое значение мирового искусства и его роль в развитии гуманизма в истории человечества.

Вопреки общественным катаклизмам духовная культура, к которой принадлежит искусство, не претерпела в истории значительных разрушений. Она веками накапливала свои богатства. Существуют если не сотни, то по крайней мере десятки определений культуры. Здесь не стоит в них разбираться. Отмечу только, что бесспорным и несомненным является различие материальной и духовной культуры. Оно относительно, ибо в созданной человечеством среде обитания, так называемой второй природе, проявляются также его духовные потребности и «лицо» общества, а духовная культура имеет материальную основу. Тем не менее, это разные сферы общественного бытия. Обе они - результат творческой, созидательной деятельности, но при этом духовная культура относительно самостоятельна, автономна и самоценна. Она - содержательное наполнение общественной истории, как и жизни индивида, главный признак, отличающий человека от животного.

Духовная культура проявляется в религии, морали, гуманитарных науках, философии, искусстве - и в искусствознании, которое есть не только прикладная наука для обслуживания деятелей искусства и художественных учреждений и не просто сфера просвещения для воспитания вкусов и пополнения образования зрителей, а особая область духовной культуры, которая через постижение искусства приобщает людей к самым высоким вершинам эстетического созерцания, красоты, чувства и мысли. Отдельные искусствоведческие дисциплины могут быть посвящены специальным частным вопросам, но искусствознание в целом, в своей сущности - наука не только об искусстве, но и о жизни, понятой через искусство. Поэтому оно и составляет область духовной культуры.

Внутренний мир человека, его индивидуальность и характер, психология личности включают в себя в сложном переплетении различные грани духовной культуры человечества, во многом влияя на жизненную судьбу. И чем богаче духовный мир человека, тем более велики, при прочих равных условиях, его творческие возможности, его достоинство и нравственная высота. Прибегая к метафоре, можно сделать парадоксальное утверждение: чем тяжелее духовный багаж, тем легче с ним идти по жизни.

Духовная культура, с одной стороны, зависит от материально-технического прогресса, а с другой противостоит ему. Театральные здания, концертные залы, галереи и музеи, музыкальные инструменты и сценическое оборудование, фото и киноаппаратура - все это и многое другое, что составляет материальную основу духовной культуры, совершенствуясь вместе с техническим прогрессом, дает новые возможности и для ее развития. Но вместе с тем она противостоит бездуховности, порождаемой культом богатства, власти денег и материальных ценностей, которые нивелируют ее достижения, ведут к ее падению, порождают мир пошлости и гламура, примитивного китча и неразвитого вкуса, абсолютизацию чувственных удовольствий и развлечений.

А на другом полюсе художественной жизни постмодернистские заморочки с их рассудочно выдуманными артефактами, претендующими на подлинное искусство. Они тоже результат падения духовной культуры: в лучшем случае - лишь формальный эксперимент, материально-композиционный поиск, необходимый в художественном развитии, но еще не ставший настоящим искусством, в худшем же случае - вообще лежат за гранью художественной культуры.

Вот и выходит, что духовная культура - гарант сохранения человеческого существования и общественного будущего, а люди, посвятившие себя ее развитию, ответственны за ее сохранение и усиление ее роли в обществе, особенно когда это будущее под вопросом.

А оно под вопросом. Сейчас в мировой науке активно обсуждается проблема - к чему идет человечество: к гибели или к новой ступени своего развития. То, что ныне мы переживаем некий переходный период, очевидно, но направление развития неясно. Когда-то Н. В. Гоголь в «Мертвых душах», уподобив Россию птице-тройке, несущейся в неведомые дали, вопрошал: «Русь, куда ж несешься ты? Дай ответ. Не дает ответа». Этот гоголевский вопрос остается актуальным и ныне. И ответа на него тоже нет. Мы не знаем, куда сейчас несется не только наша страна, но и все человечество. Однако об этом стоит подумать. Попробуем поразмыслить.

В техногенную эпоху научно-технический прогресс приобрел для человечества приоритетное значение потому, что в производительных силах находили главный стимул развития общества, а также источник богатства и власти. На него ныне уповают и в размышлениях, концепциях, теориях о будущем человечества. Считают, что именно дальнейшее беспредельное развитие науки и техники поможет 
избежать гибели человечества от истощения природных ресурсов или от глобальных и космических катаклизмов и катастроф. Вооруженное невиданными и мощнейшими достижениями в этой сфере, перед угрозой природной гибели, наука и техника помогут человечеству выжить, а если надо, то и переселиться на Луну или на другую планету, под землю или в глубины океана... Подобные утопии закономерное порождение приоритетности научнотехнического прогресса и представлений о его бесконечности и безграничных возможностях.

Разумеется, научное исследование и космоса, и океанских глубин, и недр земного шара важно для общественной истории и практической деятельности людей. Но биологическая природа человека, хотя она в определенных пределах и подвержена некоторому развитию, не может измениться коренным образом. Человек может временно, с научноисследовательскими целями, проникать в чуждые ему сферы бытия, но человечество в целом никогда не сможет обитать в них постоянно. Создание искусственной среды обитания при огромных достижениях науки и техники возможно отнюдь не как будущее всего человечества, ограниченно во времени и приспособлено для небольшого количества лиц.

Для изучения и прогнозирования будущего в $\mathrm{XX}$ в. возникла особая наука - футурология. Наука эта имеет позитивистский, а не философский характер. Ученые-футурологи, вооруженные новейшими информационными технологиями, высчитывают, что будет с теми или иными отраслями экономики, демографии или другими сторонами человеческой жизни через 10, 20, 30 лет. На этой основе делаются прогнозы и даются рекомендации для тех или иных управленческих и властных структур. Это приносит пользу как вспомогательный и дополнительный источник информации. Но футурологические прогнозы во многих случаях оказываются неточными, а иногда и вообще несостоятельными, ибо не учитывают неожиданные, непредвиденные обстоятельства и случайности. И хотя в чем-то они могут помочь управленцам, но предсказать будущее человечества не в состоянии.

Позитивистская футурология исходит из ложной предпосылки о бесконечности научно-технического прогресса и о безграничности техногенной цивилизации, сделавшей прогресс приоритетом исторического развития. В противовес этому я выдвигаю гипотезу, что техногенная цивилизация - только этап, пусть длительный и могущий еще достаточно долго длиться, но все-таки только этап в истории человечества, который, как и всякий этап, имеет свой конец и свою границу.

Египетская, античная, средневековая и другие докапиталистические культуры не были техногенными. Там господствовали другие приоритеты.
Предполагаю, что не будет техногенным и будущее человечества. Европейско-американская цивилизация Нового времени не абсолют, а преходящее завоевание общественной истории, которое уже сейчас начинает исчерпывать себя.

Поскольку научно-технический прогресс приносит и далее будет приносить различные внешние блага жизни, человечество само от него никогда не откажется. Не изменят направление исторического развития и могущие возникнуть рационалистические проекты, облеченные в научную форму, ибо по таким выдуманным из головы проектам история никогда не развивалась, о чем свидетельствует хотя бы опыт крушения СССР и других рационалистически рожденных деспотий.

Тем не менее, техногенная эпоха рано или поздно закончится даже вопреки воле и желаниям людей. Научно-технический прогресс не просто испытает кризис, а впадет в коллапс. Причины этого могут быть многие и различные. Но достаточно представить себе хотя бы следующую ситуацию. Известно, что научно-технический прогресс имеет не только позитивные, но и негативные последствия, в частности экологические. Сопровождающее его изничтожение лесов, истощение почв и недр, исчезновение многих видов живых существ, загрязнение воды и воздуха - все это оказывает отрицательное воздействие на эволюцию, биосферу и климат нашей планеты; положительного воздействия не существует. На ликвидацию и предотвращение негативных последствий затрачивается все больше и больше материальных средств, ибо разрушительные силы возрастают вместе с техническим развитием. И неизбежно настанет момент, когда негативные последствия станут значительнее позитивных и затраты на них превысят стоимость самого прогресса. А это уже причина для коллапса. Существуют и другие причины.

Прежняя критика романтиков и реалистов, показавших связь научно-технического прогресса с общественными пороками и деградацией личности, в полной мере сохраняет значение для современности - разумеется, с поправкой на новое историческое время и новые формы тех же тенденций. Укажу лишь некоторые.

Научно-технический прогресс закономерно и неизбежно порождает безмерно растущую во всех цивилизованных странах, в том числе и у нас, бюрократизацию всех сфер жизни. С возрастанием его сложности (а оно лежит в самой природе прогресса) возрастает значение и усложнение и государственных структур, и общественных отношений, а это порождает все большую бюрократизацию административных и общественных процессов. Они обрастают горами оформляющих их ведомственных бумаг, инструкций, указаний, разрешений и запрещений, поручений, предписаний, отчетов и т. п. 
Разбухает вместе с этим и армия чиновничества, в которой, как и во всякой армии, немало обезличенного. Власти порою пытаются бороться с разрастанием бюрократии и кое-что время от времени упрощают и сокращают. Но все это оказывается паллиативом. В двух-трех местах что-то меняется, а в целом бюрократическая машина становится все грознее и опаснее. Она напоминает многоголовую сказочную гидру, которой отсекают одну голову, а у нее вместо этого вырастают три новые.

Рост бюрократизации вызывает и рост коррупции. Источник ее - не только стремление отдельных чиновников к наживе и не только способ преодоления у части работающих нищенских зарплат, но часто и следствие попытки преодолеть бюрократические барьеры, требующие таких проволочек, волокиты и потери полезного времени, что у людей опускаются руки. Не желая попусту и бессмысленно тратить время и силы на горы псевдонужных бумаг, они прибегают к единственному способу эффективного преодоления бюрократического чудовища - взятке. С этим власти тоже пытаются бороться: сажают отдельных чиновников, устраивают показательные судебные процессы. Но все это также паллиатив. С коррупцией, конечно же, надо бороться. Но эта борьба лишь сдерживает процесс, а не подрывает его в корне. Коррупция будет расти с ростом бюрократии и усложнения государственных структур, что вызывается самой сутью научно-технического прогресса. Бюрократизация со временем, словно короста, покроет все человечество, сделает его больным и язвенным. И это тоже - одна из причин коллапса научнотехнического прогресса: без роста государственной бюрократизации он не может развиваться, она же станет и одним из его могильщиков.

Еще одна проблема связана с падением гуманитарного образования. С прогрессом непрерывно возрастает (и далее все более будет возрастать) объем накопленных человечеством знаний, научной и другой многообразной информации. Учеными подсчитано, что впервые удвоение всего количества существующей в мире информации произошло в период от Христа до Леонардо да Винчи, т. е. примерно за 15 веков; теперь же объем мировой информации удваивается каждый раз за одну неделю. От информационного бума сотрясаются все системы традиционного образования. Оно реформируется в сторону все большей специализации, утилитаризма, сокращения гуманитарных знаний и общей духовной культуры. Специализация лихорадочно обновляется и дифференцируется, а духовность тает.

В общеобразовательных школах изъяты из обязательных программ уроки пения и рисования. К смешному минимуму сведена художественная литература, причем порою замахиваются ее совсем убрать. Из вузов изгнана эстетика. Повальное увлечение компьютерами и интернетом вытесняет чтение книг. Но никакие новейшие информационные технологии не компенсируют «убытки» от всего этого. Нынешняя система образования ведет к ограниченности сознания, к узости представлений, к духовной бедности даже в случае обширности специальных профессиональных знаний, т. е. в конечном счете к деградации личности.

Я говорю сейчас не о специальных гуманитарных колледжах, вузах, научных институтах, где многое достигается в развитии духовной культуры. Речь идет об образовании в других сферах, о массовой подготовке новых поколений. И больно видеть, как узкая специализация подменяет широкий взгляд на мир и общую культуру молодежи. Тревожно, когда человек становится односторонним, а его личность не развитой.

Вынужденные прогрессом эксперименты с реформой образования только ухудшают дело. Из противоречия между узкой специализацией и всестороним развитием личности не могут найти оптимальный выход. Да и может ли он быть найден в современных условиях? Политические лидеры стремятся подчинить образование научно-техническому прогрессу, люди же их заботят лишь как составная часть производительных сил и объект власти. Обесценение и усреднение личности становится питательной почвой для манипуляций массовым сознанием со стороны властей. По мере широчайшего развития средств массовой информации возможность манипуляций невероятно возросла. И противостоять им свободным и самостоятельно мыслящим людям становится все труднее. Усиление административного ресурса ведет к застою в обществе, к подавлению демократии и протестных движений, консервации истеблишмента.

Негативные последствия научно-технической революции сказываются на обществе также и опосредованно, через их влияние на природу. Подземные ядерные взрывы, засорение космоса, вредные отходы промышленности, в том числе ядерной и химической, непредвиденные выбросы в атмосферу углекислого газа в конечном счете влияют на климат и ведут к бедственным для людей катастрофическим сдвигам. Технологии и природа начинают действовать заодно - и против людей.

Но техногенной эпохе придет конец. Она прекратится не оттого, что общество от нее откажется или будут придуманы разумные проекты ее изменения, а оттого, что противоречия научно-технического прогресса, возрастание его негативных последствий приведет рано или поздно к грандиозной глобальной катастрофе, в которой, возможно, погибнет значительная часть людей, населяющих нашу планету, но которая изменит направление исторического развития. 
Оставляю сейчас в стороне гибельные для человечества природные катаклизмы вроде землетрясений, извержений вулканов, цунами, падения метеоритов и т. п.: они от нас не зависят. Говорю лишь о том, что является нашим собственным порождением. Техногенная цивилизация рухнет из-за внутренних противоречий, которые сделают невозможным дальнейшее развитие, из-за коллапса, к которому они приведут (подобно транспортным коллапсам, возникающим из-за автомобильных пробок на дорогах). Научно-технический прогресс рано или поздно выйдет из под контроля, взорвется и раздавит людей.

Речь идет не об Апокалипсисе. Человечество не погибнет (уничтожит ли его природа - это другой вопрос). Даже если в глобальной техногенной катастрофе выживут немногие, то постепенно человечество возродится. И тогда возникнет другая, не техногенная эпоха, где некоторые достижения предшествующей цивилизации сохранятся, но развитие техники приобретет ограниченный характер, строго согласованный с духовными потребностями людей и с экологическими законами. Главное же он потеряет приоритетное значение в развитии общества. Приоритетными станут ценности иного рода, прежде всего гуманитарного и духовного характера. Техника не исчезнет, но будет подчинена не комфорту, роскоши и богатству, а духовным, идеальным потребностям и задачам (при обеспечении необходимого, но достаточного материального существования людей). Отсюда - великое значение сохранения и развития духовной культуры.

Не следует думать, что я мечтаю о возврате к доцивилизованному времени, к архаике и примитиву. Отнюдь нет. Посттехногенная эпоха будет более высоким этапом в развитии человечества, где технологическая основа в необходимых и достаточных формах останется, приоритет же получит духовная культура. Возобладают гуманистические ценности, веками накапливавшиеся и развивавшиеся в искусстве, философии, нравственных и гуманитарных науках, в религии. Именно они, отодвинутые в предшествующей и современной истории на второй план, станут определять развитие человечества.

Я далек как от намерений романтиков начала XIX в. вернуться к докапиталистическому времени, так и от толстовского опрощенчества и отказа от городской цивилизации (толстовцем и мужиком становиться не собираюсь). Далек я и от стремлений увидеть идеал в первобытности, что грезилось критикам современной цивилизации: Р. Вагнеру в «Кольце Нибелунга», П. Гогену в таитянских картинах, Н. К. Рериху в гималайских циклах, И. Ф. Стравинскому в «Весне священной», С. С. Прокофьеву в «Скифской сюите». Их грезы дали изумительные художественные результаты, которые будут жить вечно как взлеты человече- ского духа и вершины прекрасного, но как философские концепции они принадлежат своему времени. Поэтому я веду речь о том, что восхождение человечества на более высокую ступень исторического развития будет связано с вынужденным (не добровольным) прекращением техногенной цивилизации в результате ее собственной катастрофы. Эту катастрофу оно не планирует - наоборот, всеми силами стремится избежать и предотвратить. Но избежать ее в силу объективного хода вещей не удастся. Встав в свое время на рельсы научно-технического прогресса, человечество не может с них сойти, а они рано или поздно приведут в пропасть. Повторю: дальнейшее развитие будет определяться гуманитарными потребностями и задачами; решающее значение приобретет идейная парадигма времени, которой сейчас нет, но которая появится с новой эпохой. Не красота спасет мир, как думал Ф. М. Достоевский. Ее одной для этого недостаточно, она слишком хрупка и беззащитна. Спасет мир духовная культура в целом, с ее веками накапливавшимися богатствами.

Возможно, мою концепцию многие сочтут утопией, чистым субъективным предположением. На большее я и не претендую, пророком быть не собираюсь. Однако и гипотезы имеют право на существование, особенно если для них есть предпосылки. А они, напомню, таковы: в современном мире научно-технический прогресс становится все более безумным, алогичным, неуправляемым, угрожающим; весьма спорно, чего он приносит человечеству больше - добра или зла (утверждение Ж.Ж. Руссо о том, что технические достижения не делают людей счастливее, сохраняет актуальность); возникает вопрос - не делают ли они людей несчастнее, не обесчеловечивают ли их, не порабощают ли техникой, не ставят ли их на грань катастрофы и самоуничтожения. Ответить на этот вопрос может только история. Но думать об этом, высказывать обоснованные предположения необходимо. Без этого труднее будет, если и не избежать исторического тупика, то хотя бы понять и преодолеть его.

Внутри научно-технического прогресса в современную эпоху есть обнадеживающая тенденция, о которой необходимо сказать. Наше время характеризуется активно идущими процессами глобализации, т. е. тенденцией к единению всего человечества, охватывающей самые разные сферы бытия. Как бы ни боролись против нее антиглобалисты, глобализация - неизбежный, необходимый, объективный процесс. Идет она и в сфере культуры. И здесь, как и в других областях, имеют место свои издержки и негативные стороны. Мы часто перенимаем из других культур не только хорошее, но и плохое; чрезмерное увлечение процессами глобализации может создать угрозу для национальных основ той или иной куль- 
туры. Но в целом глобализация - позитивный процесс. Она расширила культурные горизонты и создает возможности для обогащения отечественной культуры достижениями других народов, что способствует сохранению и развитию духовных ценностей.

Однако хороша не всякая глобализация. В истории (от Александра Македонского до А. Гитлера) были попытки завоевать мир, т. е. достичь глобализации на военной основе. Все они провалились. В современном мире это тем более невозможно, что атомная война приведет не к единению, а к гибели всего человечества. Американский подход к глобализации состоит в том, чтобы овладеть миром на экономической основе: купить его или принудить к подчинению многообразными экономическими способами. Кое-что США в этом отношении удается, и они остаются лидерами глобализации. Но сопротивление им столь велико, что уже сейчас ясно: этот способ также окажется несостоятельным, как и военный.

Какая же глобализация может быть плодотворной, продвинуть человечество к новым вершинам? Гуманитарная. Поясню, что это значит. Многие мыслители и деятели искусства прошлого мечтали о единении человечества. Достаточно напомнить о Девятой симфонии Л. ван Бетховена, в финал которой включены вокальные партии хора и солистов на слова «Оды к радости» романтического поэта Ф. Шиллера, где ключевыми являются призыв «Об- нимитесь, миллионы!» и образ радости, слетающей с небес для объединения всех людей. Это была великая утопия; но то, что когда-то было утопией, в будущем может стать реальностью. В современном мире есть предпосылки для единения всех стран на гуманитарной основе духовных ценностей, добра и взаимопомощи при сохранении автономии и самостоятельности каждой страны. Гуманитарная глобализация - вот идеал. Разумеется, она предполагает определенную интеграцию в экономической, политической и других сферах, в процессе которой лидерство может переходить от одной страны к другой, но будет исключено господство и насильственное подавление одних другими.

Гуманитарная глобализация может стать реальностью лишь с окончанием техногенной цивилизации. Но уже сейчас ее признаки и предпосылки существуют и кажутся тем лучом света в конце тоннеля, который поможет выйти из современного кризиса. Подождем. Время покажет. А пока будем утверждать и в творчестве, и в научных исследованиях, и в критике принципы и критерии высокого искусства и подлинной духовной культуры, опирающиеся на высшие достижения мировой художественной классики и на вершины человеческой мысли. Если не мы, то кто же сможет эти достижения сохранить и развить? Хочу надеяться, что мы окажемся достойны выполнения этой исторической миссии.

\section{Список литературы:}

1. Белозерцев В. И. НТР и духовное производство. Ульяновск, 1985 .

2. Беньямин В. Произведение искусства в эпоху его технической воспроизводимости. М., 1996.

3. Бычков В. В., Маньковская Н. Б. Современное искусство как феномен техногенной цивилизации. М., 2011.

4. Волков Н. Г. Истоки и горизонты прогресса. М., 1976.

5. Еремин С. Н., Семенов Е. В. Наука и образование в системе НТР. Новосибирск, 1986.

6. К К Клова Е. Н. Художественная культура и НТР. Ташкент, 1983.

7. Коган Л. Н. Культура и НТР. Саратов, 1987.

8. Козиков И. А. Диалектика социальной и научно-технической революции. М., 1987.

9. Медоуз Р. Пределы роста. М., 2007.

10. Научно-техническая революция, человек, его природная и социальная среда. Л., 1977.

11. Общественное развитие и НТР. Л., 1982.

\section{References (transliteration):}

1. Belozertsev V. I. NTR i dukhovnoe proizvodstvo. Ul'yanovsk. 1985.

2. Ben'yamin V. Proizvedenie iskusstva v epokhu ego tekhnicheskoy vosproizvodimosti. M., 1996.

3. Bychkov V. V., Man'kovskaya N. B. Sovremennoe iskusstvo kak fenomen tekhnogennoy tsivilizatsii.

4. Volkov N. G. Istoki i gorizonty progressa. M., 1976.

5. $\quad$ Eremin S. N., Semenov E. V. Nauka i obrazovanie v sisteme NTR. Novosibirsk, 1986.

6. Kislova E. N. Khudozhestvennaya kul'tura i NTR. Tashkent, 1983.

7. Kozikov I. A. Dialektika sotsial'noy i nauchno-tekhnicheskoy revolyutsii. M., 1987.

8. Kogan L. N. Kul'tura i NTR. Saratov, 1987.

9. Nauchno-tekhnicheskaya revolyutsiya, chelovek, ego prirodnaya i sotsial'naya sreda. L., 1977.

10. Obshchestvennoe razvitie i NTR. L., 1982. 